\title{
Physiology, Productivity and Cotton Plant Adaptation under the Conditions of Soil Salinity
}

\author{
Norboyeva Umida Toshtemirovna, Kholliyev Askar Ergashovich
}

\begin{abstract}
The article presents the results of the influence of soil salinity on some physiological parameters and productivity of cotton varieties. It was established that the change in the value of the studied parameters within the limits of varieties from salinity and the degree of soil moisture. At the same time, the resistance of cotton varieties Bukhara-102 and Bukhara-8 to soil salinity depending on the varietal characteristics was established.
\end{abstract}

Keywords : cotton, soil salinity, physiological parameters, water exchange, productivity, yield.

\section{INTRODUCTION}

The study of the mechanisms of plant defense reactions at salinity is an actual problem of modern plant physiology, since the number of saline soils increases every year due to artificial irrigation of fields. In this aspect, the identification of plants with increased resistance to this factor is one of the important tasks of agricultural practice [1,328-335].

The negative effect of salinity on plant growth and development has two main components: moisture deficiency due to osmotic stress and the toxic effect of excess salt ions, especially $\mathrm{Na}+$ ions, due to impaired ionic homeostasis [2.41-101].

High concentrations of salts in the soil inhibit the growth processes of young plants, reduce the activity of many important physiological reactions, which ultimately leads to premature aging and death of adult plants [3,651-681]. One of the reasons for the decline in crop productivity is various forms of abiotic stress, among which salinity plays an important role [4,87-94].

The value of this stress factor in recent years has been increasing, including as a result of human economic activity[5,66-71]. Since plants cannot actively avoid exposure to stress, they react to it, mainly at the cellular level [6,3168-3185; 7,1041-1052; 8,25-35; 9,209-219].

Accordingly, the knowledge of plant response mechanisms to abiotic stress is important, as in theoretical. Particularly to create new forms of plants with increased resistance to stress are included to the plans.

Under conditions of salinity of the soil and the unfavorable climate of the Bukhara region, studies of growth and development, crop yields and especially the physiological characteristics and productivity of new zoned

Revised Manuscript Received on July 22, 2019.

Norboyeva Umida Toshtemirovna, PhD (Biology) Bukhara State University, Bukhara, Uzbekistan

Kholliyev Askar Ergashovich, DSc (Biology) Bukhara, State University, Bukhara, Uzbekistan, askar-27@mail.ru and promising cotton varieties were not carried out.

\section{RESEARCH METHODS}

The studies used medium-fiber (Gossypiym hirsutum L.) cotton varieties Bukhara-6, Bukhara-102, Bukhara-8, Bukhara-10 and C-6524. The purpose of the research was to study the characteristics of some physiological parameters and productivity of cotton varieties in soil salinity of the Bukhara region.

To study the effect of soil salinity on water exchange and productivity of cotton varieties, laboratory, vegetation and field experiments were conducted. To create a weak, medium and high degree of soil salinity used $\mathrm{NaCl}$. In field experiments, the soil was characterized by a mixed sulfate-chloride type of salinity with a predominance of chloride salinity, which is typical of the Bukhara region. Different soil moisture was created based on the full capacity of the soil.

\section{RESULTS AND THEIR DISCUSSION}

Salinity of the soil, adversely affecting the process of water exchange in all studied cotton varieties, changes the physiological and biochemical processes. We have identified the dependence of the intensity of water exchange of the studied cotton varieties on the degree of soil salinity.

In laboratory experiments, the negative effect of the degree of salinity on germination, initial growth and morphophysiological features of cotton was revealed. In variants of 50\% soil moisture from full moisture capacity, a strong influence of soil salinity on the morphological, biological and physiological indicators of cotton was observed. With an increase in soil salinity, changes in morphophysiological indicators (stem height, leaf surface, root volume, wet weight of seedlings, total water content, turgid condition) in seedlings of all studied varieties were noted.

Soil salinity in all variants of the experiment led to a decrease in the intensity of transpiration, an increase in the water-holding capacity of the leaves. Under the influence of soil salinity, the ratio of total, metabolic and bound water changes. With an increase in the degree of salinity, the amount of total and bound water increases, the amount of metabolic water decreases, and the water deficiency of leaves and the concentration of cell sap increase. Salinity of the soil leads to a decrease in water potential and chlorophyll content. The viscosity of the protoplasm, the albumin 
content increases in all variants of experience in all varieties of cotton under the action of soil salinity. The intensity of photosynthesis decreases to varying degrees under the conditions of salinity in all studied cotton varieties.

The growth rate of cotton varieties directly depends on the salt content in the soil, i.e. the degree of salinity. A noticeable effect on growth processes was observed with strong salinity and under conditions of soil drought. The growth of the experimental plants was $13-25 \%$ lower than the control. In variants with optimal soil moisture, growth processes were more active. With an increase in salt concentration in both variants of moistening, the growth of plants of all varieties slowed down. The degree of soil salinity has a different effect on plant growth in different varieties.

With an increase in the degree of salinity, a decrease in leaf area was observed in all varieties. Such a decrease was stronger in variants with soil drought. The leaf area of all varieties increased from the budding stage to fruiting. The minimum leaf area was observed in the experimental variants with strong salinity.

The net productivity of photosynthesis of the studied cotton varieties in field experiments was dependent on the degree of salinity and soil moisture. An increase in the degree of salinity led to a decrease in photosynthetic productivity in all cotton varieties. Such a decrease was greater in variants with soil drought.

An increase in the degree of soil salinity, as a result, leads to a decrease in the mass of raw cotton in boxes. The average weight of cotton in boxes in the variants with strong salinity was less $(4.2 \mathrm{~g})$. In the variants with salinity and water deficiency was even less $(3.3 \mathrm{~g})$. Salinity of the soil also negatively affects the quality of the crop: the fiber length and the weight of 1000 cotton seeds are reduced. A sharp deterioration in the quality of the crop was observed with a joint effect of soil salinity and drought compared with the variants of optimal moisture. With increasing soil salinity, cotton productivity also decreases. The combined effect of soil salinity and drought leads to a 1.5 -fold decrease in yield.

In field experiments, the effect of soil salinity and the degree of water availability on the productivity of cotton varieties was also studied. The productivity of cotton varieties differed depending on the degree of salinity and water availability. In all experimental variants with soil moisture of $70 \%$, yield was reduced from 3 to 30 percent compared to the control. Such a decrease was greater in the variants with strong salinity of the soil. In variants with soil moisture of $50 \%$, a sharp decrease in yield was observed. It ranged from 6 to $46 \%$ compared with the control in different varieties.

Under the conditions of soil salinity, a decrease in the biological and economic yield of all varieties was observed.

The differences in the yield of the studied varieties depending on soil salinity are associated with the biological characteristics of these varieties of cotton. The reduction in the quantity and quality of the harvest in salt-resistant varieties Bukhara-102 and Bukhara- 8 compared with other varieties was less.

As a result of the experiments, the dependence of the productivity of cotton varieties on the degree of salinity was noted. Salinity of the soil has a noticeable effect on the morphophysiological characteristics of the studied cotton varieties. The growth of plants in all varieties is reduced under conditions of salinity, the leaf surface decreases. The net productivity of photosynthesis was significantly less in terms of salinity compared with the control. As a result, salinity had a strong impact on the crop and its quality. The combined effect of soil salinity and drought, changing the water balance of the studied cotton varieties, has led to a decrease in crop size and its quality.

The dependence of the productivity and rate of water exchange in all studied cotton varieties on the degree of salinity and soil moisture was found. The inverse dependence of growth, leaf area, net photosynthesis productivity, yield and its quality on the degree of soil salinity is shown. Such a sharp decrease was observed at $30 \%$ soil moisture content of full water capacity (PV).

The greater the ability of a species or variety to be modified in accordance with its environment, the wider its reaction rate and the greater its adaptability. This property is distinguished by resistant varieties of crops. As a rule, slight and short-term changes in environmental factors do not lead to significant disturbances in the physiological functions of plants. This is due to their ability to maintain the relative dynamic equilibrium of the internal environment and the stability of basic physiological functions in a changing external environment. At the same time, sharp and prolonged exposure leads to the disruption of many functions of the plant, and often to its death.

\section{Conclusion}

The adaptation reactions of the studied cotton varieties (Bukhara-6, Bukhara-102, Bukhara-8, Bukhara-10 and C-6524) to soil salinity of various degrees depended on the biological characteristics of these varieties. The degree of resistance of varieties depended on water metabolism and a number of physiological processes. With the combined effect of soil salinity and drought, there was a decrease in varying degrees of the adaptive potential of the studied varieties, which was reflected in a decrease in the amount of raw cotton and a decrease in its quality.

Under the conditions of soil salinity in all experiments, a comparatively high and high-quality crop was obtained with the Bukhara-102 and Bukhara-8 varieties. With soil salinity, especially its combined action with drought, a sharp decrease in yield and quality in C-6524 varieties was revealed.

When cultivating the studied cotton varieties in areas with varying degrees of salinity, it is necessary to observe timely and high-quality regional agro technical measures.

\section{REFERENCES}

[1] Кошкин Е.И. Физиология устойчивости сельскохозяйственных культур.-М.: Дрофа, 2010. -С. 328-335.

[2] Dajic Z. Salt Stress // Physiology and Molecular Biology of Stress Tolerance in Plants / Eds Madhava Rao K.V., Raghavendra A.S. Janardhan Reddy K. Dor $\neg$ drecht: Springer-Verlag, 2006. -P.41-101.

[3] Munns R., Tester M. Mechanisms of salinity tolerance // Ann. Rev. Plant Biology, 2008. V.59, №1. -P.651-681.

[4] Azevedo Neto A. D. Effect of salt stress on antioxidative enzymes and lipid peroxidation in leaves and roots of salt- tolerant and salt- sensitive maize enotypes. -In : Environmental 
and Experimental Botany, 2006, vol. 56. nr 1, -P. 87-94.

[5] Zhu J. Plant salt tolerance.-In:Trends Plant Sciences, 2001, vol. 6. nr 2. -P. 66-71.

[6] Floris M. Post- transcriptional regulation of gene expression in plants during abiotic stress.-In:International Journal of Molecular Sciences, 2009, vol. 10. nr 7, -P. 3168- 3185.

[7] Hirayama T., Shinozaki K. Research on plant abiotic stress responses in the post genome era: past, present and future.- In: Plant Journal, 2010, vol. 61, nr 6. -P. 1041 - 1052.

[8] Panchuk I. Engineering of new plants cultivars with improved abiotic stress tolerance. -In: Annals of the Stefan cell Mare University of Suceava, 2007, vol. 6, nr 1. -P. 25-35.

[9] Sanchez D. H. Plant metabolic reveals conserved an divergent metabolic response to salinity.- In: Physiology Plantarum, 2008, vol. 132, nr 2. -P. 209- 219 . 